\title{
Multiple Inoculation with Three Attenuated Viruses for the Control of Cucumber Virus Disease
} Y. Kosaka, Kyoto Biotechnology Research Center, Kitainayadzuma, Seika, Soraku, Kyoto 619-02; and
T. Fukunishi, Kyoto Agricultural Research Institute, Kameoka, Kyoto 621, Japan

\begin{abstract}
Kosaka, Y., and Fukunishi, T. 1997. Multiple inoculation with three attenuated viruses for the control of cucumber virus disease. Plant Dis. 81:733-738.

Multiple inoculation of cucumber seedlings with attenuated isolates of cucumber mosaic virus (CMV), zucchini yellow mosaic virus (ZYMV), and watermelon mosaic virus 2 (WMV-2) somewhat reduced yield loss due to mixed infection by virulent strains of these viruses in field experiments under severe epidemic conditions in 1994 and 1995. In addition, this protective inoculation largely protected grafted cucumber plants from viral wilt syndrome. In greenhouse experiments, no significant differences were observed between single and multiple inoculations in the cross-protection effects of the attenuated viruses against their respective virulent strains. Triply inoculated plants developed synergistic yellow leaf mosaic symptoms and $15 \%$ fewer marketable fruits compared with healthy plants. Thus, multiple inoculation is appropriate for the summer-early autumn production, when economic losses due to the concurrent incidence of CMV, WMV-2, and ZYMV are significantly greater than the loss in yield due to the inoculation.
\end{abstract}

It is common for an attenuated virus to display a high degree of cross-protection only against closely related strains of the same virus. Cross-protection has been used successfully to control virus diseases in several crops $(4,8)$. In Japan, efforts to obtain good attenuated virus cultures from several important viruses, including cucumber mosaic virus (CMV), zucchini yellow mosaic virus (ZYMV), watermelon mosaic virus 2 (WMV-2), cucumber green mottle mosaic virus, and citrus tristeza virus, are in progress because there are few effective cultural practices to control diseases caused by these viruses (2).

In Japan, cucumber (Cucumis sativus L.) is an important horticultural crop with approximately 20,000 ha in production. Grafting of cucumbers onto resistant squash (Cucurbita maxima $\times$ C. moshata) rootstock has been generally used to control soilborne Fusarium wilt and Phytophthora rot diseases. Currently, CMV, ZYMV, and WMV-2 are epidemic throughout cucumber-producing areas $(5,11,12,20)$. Plants are constantly threatened with simultaneous infections by these aphid-transmissible viruses. Co-infected plants exhibit severe mosaic, necrosis, and distortion of leaves and fruits, or severe wilt followed by death in grafted plants, resulting in significant yield losses $(6,18)$.

Corresponding author: Y. Kosaka

E-mail: kosaka@kab.seika.kyoto.jp

Accepted for publication 12 March 1997.

Publication no. D-1997-0428-06R

(C) 1997 The American Phytopathological Society
For this reason, a cross-protection strategy with only one attenuated virus would be unlikely to prevent damage caused by other prevalent viruses. Protective inoculation of seedlings with two or more attenuated viruses for the control of a mixed infection of unrelated viruses might be more effective. However, such a method has not yet been established for any crop.

The objective of this study was to evaluate the cross-protection effectiveness of inoculation of cucumber seedlings with three attenuated viruses (CMV, ZYMV, and $\mathrm{WMV}-2$ ) for the control of the three associated virus diseases. Parts of this work have been previously reported $(14,15,16,17)$.

\section{MATERIALS AND METHODS}

Viruses. Reactions of several indicator plants to the 11 isolates of CMV, ZYMV, and WMV-2 used in this study are shown in Table 1. C11 (designated CMV-severe), Z5-1 (ZYMV-severe), and W6 (WMVsevere) were virulent strains isolated from different field-grown cucumber plants in Kyoto Prefecture.

Attenuated $W M V-2$. An attenuated isolate WI-9 (WMV-mild) was described previously (9). This attenuated isolate and WMV-severe distinctly differed in the degree of symptom severity on squash.

Attenuated CMV. Attenuated isolates used in the greenhouse and field experiments were III-19 and CM95 (CMVmilds). The III-19 was a single-lesion isolate through Chenopodium quinoa Willd. from Nicotiana rustica L. co-infected with CMV isolates, 36a1, and Fuka4-4. The CM95 isolate was subcultured from III-19 by three serial single-lesion passages through $C$. quinoa. The $36 \mathrm{a} 1$ isolate was derived from a virulent strain occurring in Mioga (Zingiber mioga Rosc.), by low temperature treatment (13) at $12.5^{\circ} \mathrm{C}$ and additional treatment at $10^{\circ} \mathrm{C}$. This isolate produced mild symptoms on almost all plants tested and a low degree of protection on cucumber plants. In contrast, although Fuka4-4 was previously reported (10) to be excellent as a protecting strain, it induced severe symptoms on many crops except cucumber. CMV-milds were similar to $36 \mathrm{a} 1$ in attenuation characteristics and had a significantly higher protective ability than 36a1 (unpublished data). CMV-milds were qualitatively differentiated from CMV-severe in the reactions of asparagus bean (Vigna unguiculata (L.) Walp. subsp. Sesquipedalis (L) Verdc.) and bean (Phaseolus vulgaris L.).

Attenuated ZYMV. Two attenuated isolates, 20T6 and ZY95 (ZYMV-milds), were obtained from a mild strain, 2 S142a6, with poor aphid-transmissibility (3). The 2S142a6 isolate has no available local lesion host (it produces rare local lesions on Chenopodium quinoa and C. amaranticolor Coste \& Reyn.), and so screening of milder isolates was performed by repeating single-plant isolations using squash. The 20T6 was isolated after low temperature treatment (13) at 10 to $12.5^{\circ} \mathrm{C}$ for four transfers, followed by six cycles of singleplant isolation. The ZY95 isolate, which slightly delayed expressing symptoms compared to 20T6, was selected from 20T6 treated with nitrous acid ( $\mathrm{pH}$ 6.0). ZYMVmilds were significantly poorer than 2S142a6 in cross-protection effects against ZYMV-severe. However, ZYMV-milds developed more attenuated symptoms than 2S142a6 on cucurbit plants, and also less synergistic symptoms when co-infected with CMV-mild and/or WMV-mild in cucumber plants (data not shown). ZYMVmilds and ZYMV-severe were distinguishable by serological tests described below.

Inoculum sources. CMV and WMV-2 were propagated in $N$. rustica and bean, respectively. ZYMV-milds and ZYMVsevere were propagated in squash and cucumber, respectively. The propagation was conducted in a growth chamber maintained at $25^{\circ} \mathrm{C}$. Each of the infected leaves was stored at $-70^{\circ} \mathrm{C}$ before being used as a standard inoculum source.

Multiple inoculation. Leaves infected with an attenuated isolate were ground in $0.1 \mathrm{M}$ phosphate buffer ( $\mathrm{pH}$ 7.2) and di- 
luted 1:15 (wt/vol) with buffer. Carborundum-dusted cotyledons of 7- to 8day-old cucumber seedlings were mechanically inoculated by rubbing with cotton swabs dipped in inoculum or buffer. Cucumber plants were approachgrafted to squash plants 1 or 2 days after inoculation.

Plant response to viral infection. Eight-day-old seedling cotyledons of cucumber cv. Sagamihanjiro, which is highly susceptible to CMV, ZYMV, and WMV-2 (20), were singly, doubly, or triply inoculated with CMV-mild (CM95), ZYMVmild (ZY95), or WMV-mild. Control healthy seedlings were inoculated with buffer only. Twenty seedlings were used for each treatment. Symptoms were observed in the greenhouse and were scored from 0 to 4: 0 , no visual symptoms; 1 , very mild mosaic or chlorotic spots; 2 , mild mosaic; 3, mild yellow mosaic; 4, relatively distinct yellow mosaic without stunting and/or deformation. At 20 days after inoculation, all plant tissues above the cotyledon were harvested, and plant fresh weights and heights (stem length above the cotyledon) were measured.

Relative virus accumulation. Double sandwich enzyme-linked immunosorbent assay (DAS-ELISA) (1) was used to determine the relative concentrations of three attenuated viruses in the first and second true leaves of plants described above. Three disks per leaf were collected from six plants randomly sampled and assayed by ELISA at a dilution of 1:50 (wt/vol) with buffer (PBS, pH 7.4, 0.1\% [ $\mathrm{vol} / \mathrm{vol}]$ Tween 20). Diluted sap was applied to duplicate wells. Antisera to the virulent strains of ZYMV and WMV-2 (7) and the ZYMV mild strain 2S142a6 (3) were cross-absorbed with crude antigens from the other two isolates. The reactions of IgGs purified from these antisera were specific to the homologous strain. For example, the reaction differences between ZYMV-severe and 2S142a6 in DASELISA were as follows: the $\mathrm{OD}_{405 \mathrm{~nm}}$ values of a crude extract (1/10 dilution) of infected leaves, 2S142a6-IgG, 2S142a6 = 1.445 , ZYMV-severe $=0.065$, healthy plant $=0.067$; virulent ZYMV-IgG,
$2 \mathrm{~S} 142 \mathrm{a} 6=0.140, \mathrm{ZYMV}$-severe $=1.050$, healthy plant $=0.106$.

Fruit productivity. Effect of multiple inoculation with the three attenuated viruses on fruit production of cucumber was evaluated. Grafted plants (scion, cv. Sharp 5 ; rootstock, cv. Hikari Power) were grown in a screenhouse from late May to midAugust. All plants were treated with regular fungicide and aphicide. Fruit was collected every 1 or 2 days from 4 plants for 60 days in the 1995 test, or from 5 plants for 40 days in the 1996 test. Marketable fruit size was more than $15 \mathrm{~cm}$ length and $70 \mathrm{~g}$ weight.

Cross-protective activity. Greenhouse evaluation. To determine whether the cross-protection effect of each attenuated isolate was affected by simultaneous infections with the other viruses, experiments were conducted on non-grafted seedlings of cvs. Sagamihanjiro (experiment 1) and Sharp 5 (experiment 2) grown in 1.2-liter pots in a greenhouse from May to July (temperature range 20 to $35^{\circ} \mathrm{C}$ ). The cotyledons of 8-day-old seedlings were singly or triply inoculated with the attenuated viruses. Control seedlings were inoculated with buffer only. For each treatment, 24 to 26 plants were used for experiment 1 , and 10 plants were used for experiment 2 . Fifteen days after the inoculation, the third true leaves were mechanically inoculated with crude leaf extracts (diluted 1:50 [wt/vol] with buffer) carrying the virulent viruses. Observations of symp-

Table 2. Disease severity, fresh weights, and heights of Sagamihanjiro cucumber seedlings 20 days after single, dual, and triple inoculations with attenuated viruses

\begin{tabular}{lccc}
\hline Inoculum $^{\mathbf{y}}$ & Disease severity & Weight $(\mathbf{g})$ & Height $(\mathbf{c m})$ \\
\hline Mock & $0 \mathrm{a}^{\mathrm{z}}$ & $16.6 \mathrm{a}$ & $5.6 \mathrm{a}$ \\
CMV & $1.0 \mathrm{~b}$ & $13.5 \mathrm{bc}$ & $4.5 \mathrm{c}$ \\
WMV-2 & $1.0 \mathrm{~b}$ & $15.1 \mathrm{ab}$ & $5.3 \mathrm{ab}$ \\
ZYMV & $0 \mathrm{a}$ & $16.3 \mathrm{a}$ & $5.3 \mathrm{ab}$ \\
$\mathrm{Z}+\mathrm{C}$ & $2.8 \mathrm{c}$ & $14.0 \mathrm{bc}$ & $4.8 \mathrm{bc}$ \\
$\mathrm{W}+\mathrm{C}$ & $2.9 \mathrm{c}$ & $12.6 \mathrm{c}$ & $4.4 \mathrm{c}$ \\
$\mathrm{W}+\mathrm{Z}$ & $0.6 \mathrm{~b}$ & $15.4 \mathrm{ab}$ & $5.2 \mathrm{ab}$ \\
$\mathrm{W}+\mathrm{Z}+\mathrm{C}$ & $3.8 \mathrm{c}$ & $13.6 \mathrm{bc}$ & $4.8 \mathrm{bc}$ \\
\hline
\end{tabular}

y See Figure 1.

z Disease severity and plant growth were statistically analyzed by the Kruskal-Wallis ANOVA test and Tukey HSD test, respectively. Means within a column followed by different letters were significantly different at $P=0.05$. after the challenge inoculation. Plants showing indistinct or no symptoms at the final observation were assayed by backinoculation to indicator plants or by ELISA.

Field evaluation. In order to demonstrate the cross-protection effectiveness of multiple inoculation under natural infection conditions, field trials were repeated at the same two locations during 1994 and 1995, the Kyoto Agricultural Research Institute and Ujidawara, located in south part of Kyoto Prefecture. These experiments used cucumber seedlings grafted onto squash and consisted of multiply inoculated and noninoculated plots. CMVmilds used in the 1994 and 1995 experiments were III-19 and CM95, respectively. ZYMV-milds were 20T6 in 1994 and ZY95 in 1995.

At the Institute, seedlings were transplanted to a field on 25 May 1994 (30 days after inoculation) and on 29 May 1995 (19 days after inoculation). Each plot consisted of four replications (4 rows of 5 or 6 plants, with $1 \mathrm{~m}$ between plants and $2 \mathrm{~m}$ between rows). To ensure a source and good distribution of the three virulent viruses, multiply infected plants with a population of about 50 aphids (Aphis gossypii) per plant were planted (one plant per row) 1 month after transplanting.

At Ujidawara, each plot was established in a row in a grower's field from mid-June to September. Eighteen days after inocula- tom development were made for 25 days

Table 1. Reactions of several test plants to WMV-2, CMV, and ZYMV isolates used in greenhouse and field experiments ${ }^{\mathrm{Z}}$

\begin{tabular}{|c|c|c|c|c|c|c|c|c|c|c|}
\hline \multirow[b]{2}{*}{ Plant } & \multirow[b]{2}{*}{ Cultivar } & \multicolumn{2}{|c|}{ WMV-2 } & \multicolumn{4}{|c|}{ CMV } & \multicolumn{3}{|c|}{ ZYMV } \\
\hline & & W I-9 & W6 & CM95 \&III-19 & 36a1 & Fuka4-4 & C11 & ZY95 \& 20T6 & 2S142a6 & Z5-1 \\
\hline Cucumber & Sagamihanjiro & M (1) & M (2) & M (1) & $\mathrm{M}(1)$ & M (2) & M (3) & (0) & CS (2) & M (5) \\
\hline (Cucumis sativas) & Sharp 5 & $(0)$ & M (2) & CS (1) & CS (1) & $M(2)$ & M (3) & (0) & CS (2) & M (5) \\
\hline Squash & Kairyo Shintosa & M (2) & M (4) & $\operatorname{CS}(2)$ & $(-)$ & $\operatorname{CS}(3)$ & CS (4) & (0) & $M(2)$ & M (5) \\
\hline (C. maxima $\times$ C. moshata $)$ & Hikari Power & M (2) & M (4) & CS (2) & $(-)$ & $\mathrm{CS}(3)$ & CS (4) & CS (1) & $M(2)$ & $M(5)$ \\
\hline Bean (Phaseolus vulgaris) & Honkintoki & M (3) & M (3) & $M(2)$ & $M(2)$ & M (3) & L & $(-)$ & $(-)$ & $\mathrm{L}$ \\
\hline $\begin{array}{l}\text { Asparagus bean } \\
\text { (Vigna unguiculata } \\
\text { subsp. sesquipedalis) }\end{array}$ & & & & & & & & & & \\
\hline $\begin{array}{l}\text { subsp. sesquipedalis) } \\
\text { Nicotiana rustica }\end{array}$ & Kurodanesanjaku & $\begin{array}{l}- \\
-\end{array}$ & $\begin{array}{l}- \\
-\end{array}$ & $\begin{array}{l}M(2) \\
M(2)\end{array}$ & $\begin{array}{l}\text { M (2) } \\
M(2)\end{array}$ & $\begin{array}{l}\text { M (3) } \\
\text { M (4) }\end{array}$ & $\begin{array}{r}\mathrm{L} \\
M(4)\end{array}$ & $\begin{array}{l}- \\
-\end{array}$ & $\begin{array}{l}- \\
-\end{array}$ & $\begin{array}{l}- \\
-\end{array}$ \\
\hline
\end{tabular}

${ }^{2}$ Observations of symptom development were made for 1 month after inoculation. M, mosaic; CS, chlorotic spots; L, local lesions; -, not tested. Disease severity score of systemic symptoms ( ):-, not systemically infected; 0 , no visible symptoms; 1 , very mild; 2 , mild; 3 , distinct; 4, severe symptoms with malformation; 5 , grade 4 plus stunting and/or necrosis. 
tion, 60 or 70 seedlings were transplanted to a row consisting of two lines spaced 1.5 $\mathrm{m}$ apart, with plants spaced every $0.85 \mathrm{~m}$ along the line, next to a row of noninoculated control seedlings. Commercial seedlings of the same cultivar were transplanted in the rows adjacent to the experimental plots. Transplanting dates were 17 June 1994 and 23 June 1995. Each plot was maintained according to local standard practices.

Plants were scored for disease severity according to the following scale: 0 , no visible symptoms; 1 , very mild mosaic or chlorotic spots; 2, mild mosaic or mild yellow mosaic; 3 , yellow mosaic without leaf distortion or malformation; 4, severe yellow mosaic with deformation of leaves and fruits; 5, grade 4 plus stunting and necrosis or wilt. Leaf samples were collected from three parts of a plant and divided into three portions. A portion was also back-inoculated onto Honkintoki bean plants to eliminate ZYMV. The incidence of each virulent virus or each attenuated isolate was determined by reactions of test

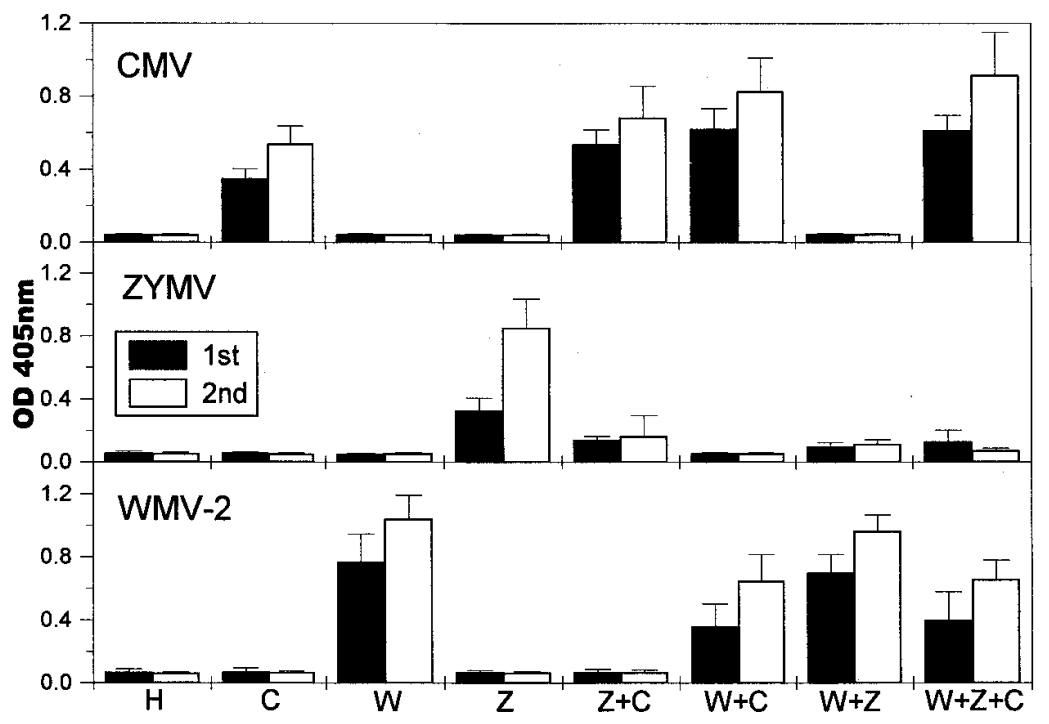

Fig. 1. Relative virus accumulation in the first and second true leaves of Sagamihanjiro cucumber plants 20 days after single, dual, or triple inoculation with attenuated isolates of CMV, ZYMV, and WMV-2. Vertical bars indicate standard errors of means. $\mathrm{H}=$ healthy plants inoculated with buffer only; $\mathrm{C}=\mathrm{CMV} ; \mathrm{W}=\mathrm{WMV}-2 ; \mathrm{Z}=\mathrm{ZYMV}$.

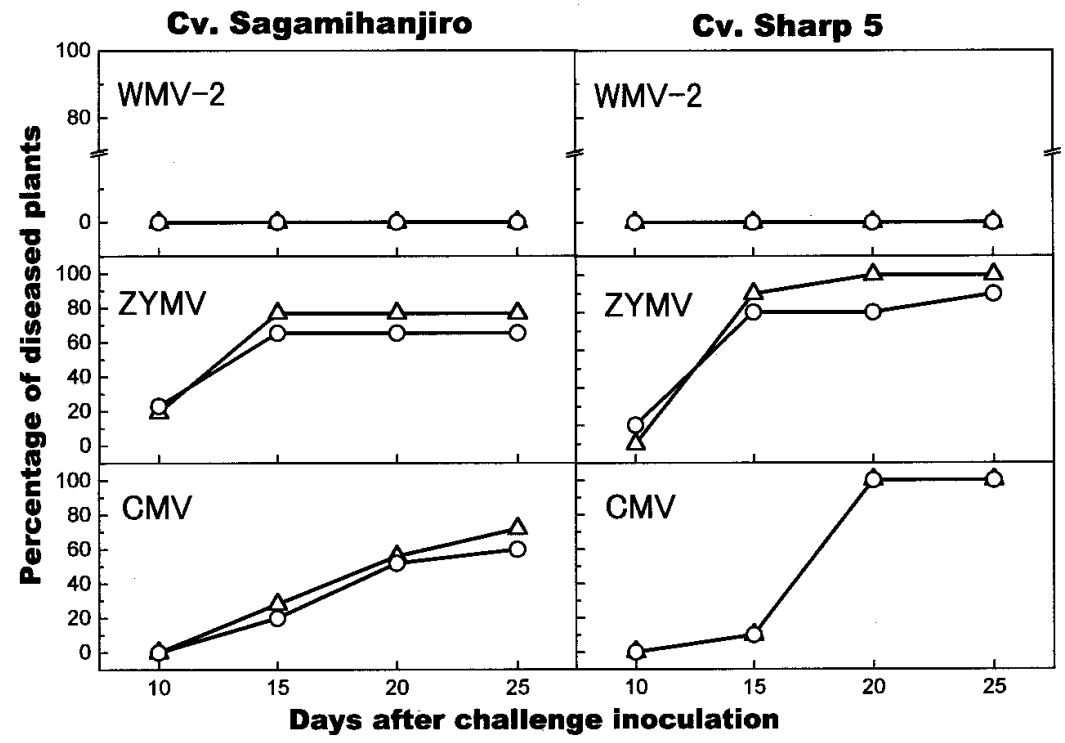

Fig. 2. The cross-protection effects on cucumber plants of single $(\Delta)$ and triple $(O)$ inoculation by attenuated viruses against the virulent strain of CMV, ZYMV, or WMV-2. None of the plants singly or triply inoculated only by an attenuated isolate of the three viruses showed severe symptoms during the period tested. All control plants that were not protected, except for the test of WMV-2 on Sharp 5 (infection rate of 90\%), showed symptoms characteristic of virulent viruses within 8 days after challenge inoculations. There were no significant differences in percentages of diseased plants for single versus triple inoculations, based on the Fisher's exact test or chi-square test of independence at $P=0.05$.

plants (CMV, asparagus bean ; WMV-2, squash) or ELISA for the field samples or back-inoculated Honkintoki bean. Marketable fruits produced in the institute's field were counted every 1 or 2 days. In the grower's field, they were weighed every day. The plants surveyed were treated with fungicide and aphicide at 7- to 10-day intervals.

\section{RESULTS}

Effect of multiple inoculation on cucumber plant. Symptom development on the first through third true leaves of Sagamihanjiro was observed for 20 days after inoculation. No symptoms were observed on plants inoculated with ZYMV-mild or buffer. Plants inoculated with CMV-mild, WMV-mild or ZYMV + WMV-milds produced very mild mosaic symptoms. On the other hand, synergistic yellow mosaic symptoms were observed on plants inoculated with CMV + ZYMV-milds, CMV + WMV-milds, or with CMV + ZYMV + WMV-milds. Significant reductions in plant fresh weights and heights were caused only by inoculations associated with CMV-mild (Table 2).

ELISA values for CMV indicated that CMV-mild accumulation was higher in dually and triply inoculated plants than in singly inoculated plants. In contrast, ZYMV values in singly inoculated plants were higher than in dually and triply inoculated plants. WMV-mild accumulation was suppressed by co-inoculation with CMV-mild while it was not affected by the presence of ZYMV-mild (Fig. 1).

Fruit production of multiply inoculated plants was assessed for 2 years. Multiply

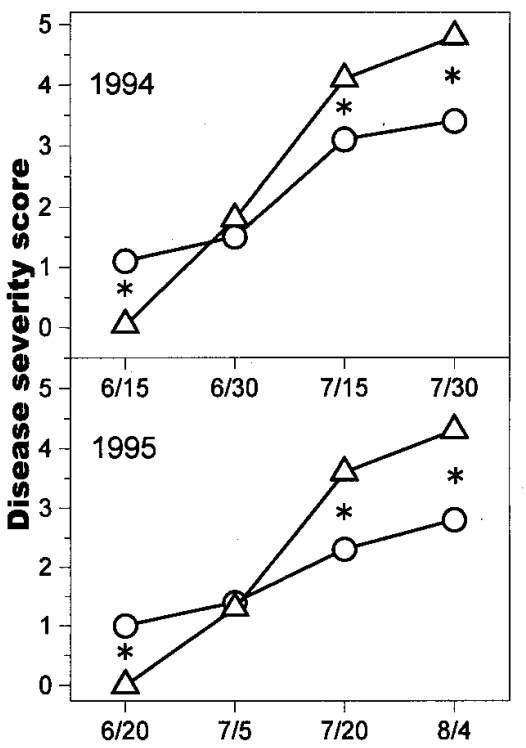

Fig. 3. Development of disease severity over time on noninoculated $(\Delta)$ and multiply inoculated $(O)$ plants with attenuated isolates of CMV, ZYMV, and WMV-2 in the field experiments. Asterisks indicate significant difference between two plots, based on the KolmogorovSmirnov two-sample test at $P<0.05$. 
inoculated plants showed mild yellow mosaic symptoms on leaves but no symptoms on fruit in the early stage of harvest. Later, the symptoms gradually became distinct. In the late stage of harvest, fruit was frequently observed with mild mosaic and/or malformed symptoms. The multiply inoculated and noninoculated plants showed significant differences in the number of symptomless fruits $(P=0.05, t$ test). Consequently, multiple inoculation reduced symptomless fruits by 25.4 to $28.6 \%$ and marketable fruits, including mild viral symptoms (chlorotic spots and/or slight malformation), by 11.3 to $15.7 \%$ compared with the control plants. Plants inoculated singly with ZYMV-mild alone showed mild mottle symptoms on leaves about 50 days after inoculation, and subsequently developed increased symptom severity. However, the effect of this single inoculation on fruit quality was significantly less than that of multiple inoculation, except for single inoculation with CMV-mild or WMV-mild, which did not affect fruit quality (data not shown).

Cross-protection effectiveness of multiple inoculation. Greenhouse experi-

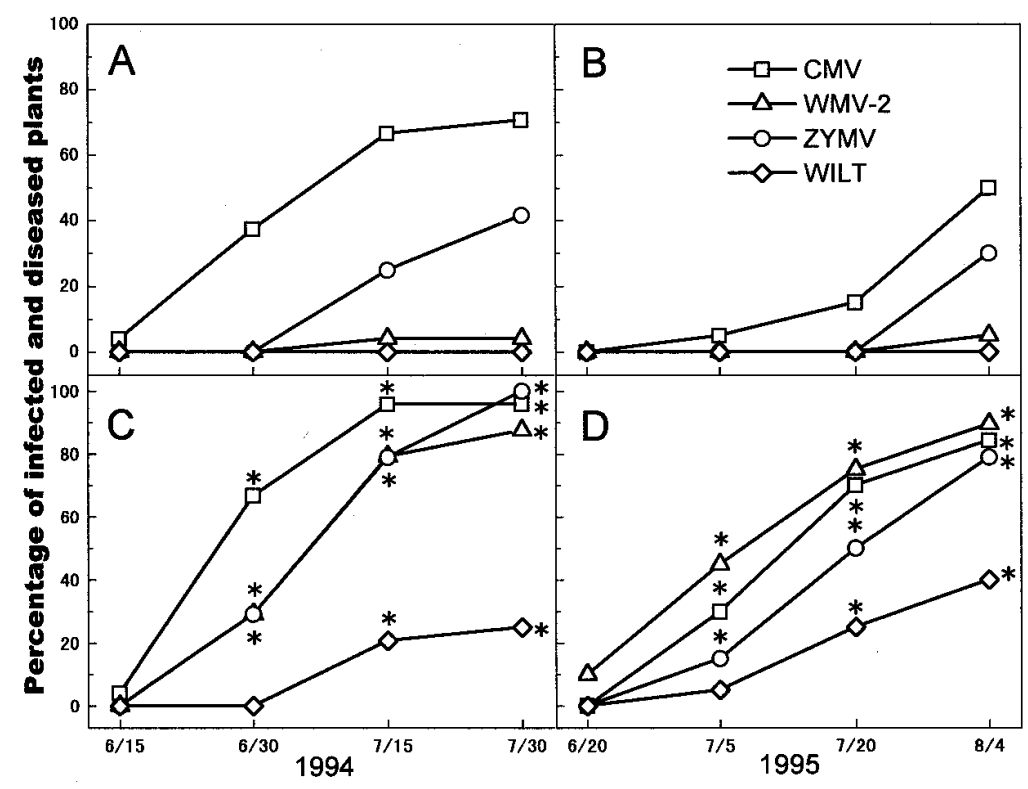

Fig. 4. Development of disease incidence over time in field cucumber plots: (A and B) inoculated with attenuated isolates of CMV, ZYMV, and WMV-2; (C and D) not inoculated. The $y$ axis represents percentages of plants infected with each of three virulent viruses and wilted plants. Asterisks indicate significant difference in the incidence of each virus between noninoculated and multiply inoculated plots in the same year, based on the Fisher's exact test or chi-square test of independence at $P=0.05$.

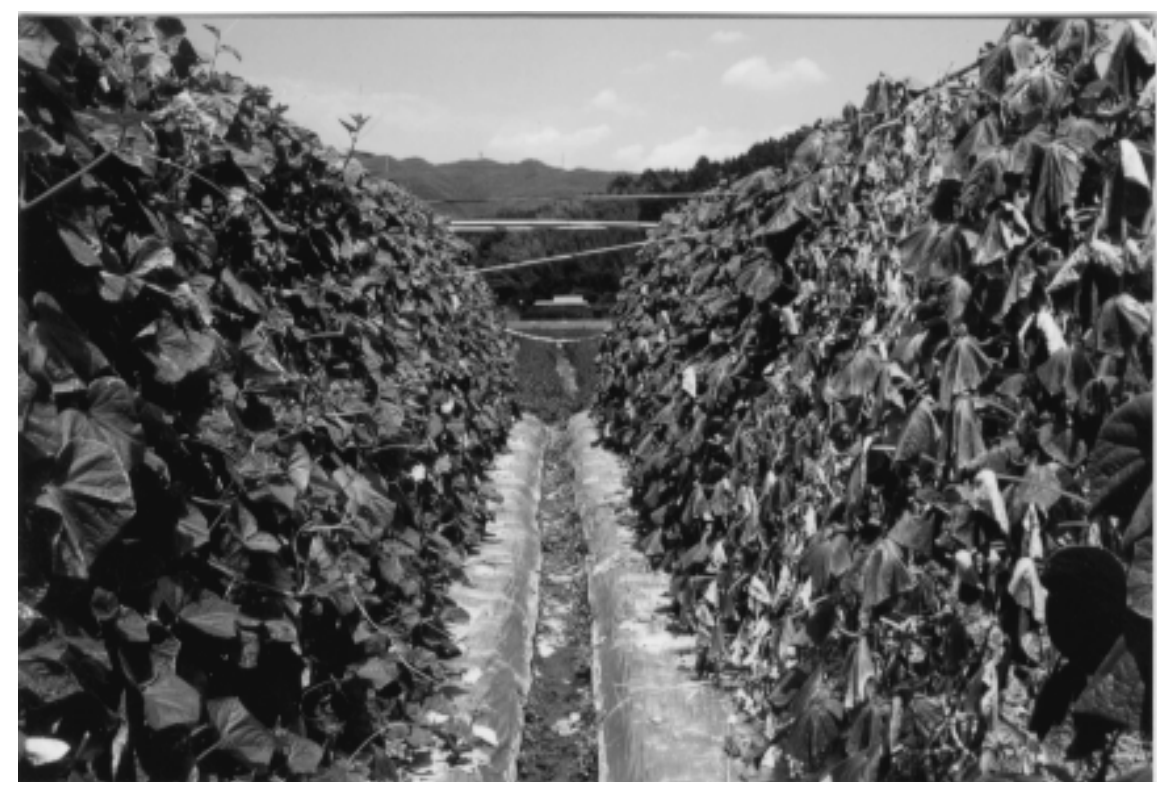

Fig. 5. Multiply inoculated plot showing no wilt symptoms (left) and noninoculated plot developing wilt symptoms (right) in the 1994 test. ments. Singly and triply inoculated plants showed the same degree of cross-protection effects against their respective severe strains. Plants inoculated with CMV-mild, ZYMV-mild, or three attenuated viruses delayed the expression of symptoms of CMV-severe or ZYMV-severe, but subsequently almost all plants developed characteristic symptoms of the virulent strains. However, the appearance of symptoms of WMV-severe were completely suppressed by both single and multiple inoculations (Fig. 2).

Field experiments. At the Institute, the stem length of triply protective-inoculated seedlings was significantly less than that of noninoculated seedlings before transplanting in 1994 and $1995(P<0.001, t$ test; data not shown). In the noninoculated control plot, disease progression curves in 1994 and 1995 tests were similar. Symptoms of viral infection first appeared in late June (about 25 days after transplanting) and subsequently disease severity rapidly progressed. At about 65 days after transplanting, almost all plants were concurrently infected with all three virulent viruses. The symptoms were extremely severe. Wilt and death due to wilting were observed in 25 and $40 \%$ of the plants in the 1994 and 1995 trials, respectively (Figs. 3 and 4).

In contrast, multiply inoculated plants exhibited very mild mosaic symptoms initially but developed yellow mosaic symptoms gradually in both years. However, inoculated plants showed lower percentages of infection with the three virulent viruses than the control plants, and produced less malformation of leaves and fruit. In addition, they did not develop wilt syndrome. Inoculated plants in the 1994 test had higher infection rates by CMVsevere and ZYMV-severe compared with the 1995 test. In both years, inoculated plants were rarely overcome with WMVsevere (Figs. 3 and 4).

The number of marketable fruits produced by noninoculated plants decreased dramatically in the latter half of the harvest $(P<0.01, t$ test $)$. The number of marketable fruit produced in the multiply inoculated plot was significantly greater $(65.5$ and $70.1 \%$ more in the 1994 and 1995 tests, respectively) than in the control plot $(P<0.01, t$ test $)$.

Table 3 shows the results of the grower's field experiments at Ujidawara. One month after transplanting, very few noninoculated plants showed viral symptoms, but nearly all the multiply inoculated plants exhibited very mild mosaic. After two months, all the control plants had developed combinations of mosaic, severe yellow mosaic, deformation of leaves and fruit, or wilt and death. Indeed, 51.7 and $21.4 \%$ of the control plants produced wilt syndrome in the 1994 and 1995 tests, respectively (Fig. 5). Virulent strains of CMV, WMV-2, and ZYMV were detected in over $66.0 \%$ of 
plants that did not die. Symptoms of the multiply inoculated plants also became severe, but their severity in the late stage of harvest was significantly less than those of noninoculated plants, because the infections by virulent strains had been suppressed in the inoculated plot. In addition, almost none of the inoculated plants produced lethal wilt syndrome, which resulted in more marketable fruit.

Natural spread of attenuated viruses. Among the leaf samples collected from the control plot during the final surveys at the institute's field in 1994 and 1995, ZYMVmild and WMV-mild were detected in $8.3 \%$ (1994) and 10.5\% (1995), respectively. No CMV-mild was discovered. At the grower's field, only CMV-mild and ZYMV-mild spread naturally to the control plot, and their rates of infection were relatively low (1994, CMV 2.0\%, ZYMV 4.0\%; 1995, CMV 6.0\%, ZYMV, 12.0\%).

\section{DISCUSSION}

Field experiments showed that multiple inoculation of cucumber seedlings with attenuated isolates of CMV, WMV-2, and ZYMV reduced yield loss due to infections by virulent strains of these viruses. It is well known that multiple infections by CMV, WMV-2, and ZYMV cause synergistic symptoms in cucumber $(6,18,20)$. Preliminary greenhouse experiments were conducted to evaluate the effectiveness of singly, dually, or triply protective-inoculated plants against triple challenge inoculations of severe strains. Plants inoculated with single or dual protecting viruses were simultaneously infected with the unrelated virulent virus(es) and produced more disease severity compared with triply protective plants. However, because the triply inoculated plants resulted in fewer marketable fruits, application of this multiple inoculation should be limited to the summer-early autumn production, when economic losses due to the concurrent incidence of CMV, WMV-2, and ZYMV are much greater than the loss in yield due to the inoculation.

No significant differences were observed between single and multiple inoculations in the cross-protection by attenuated viruses against their respective virulent strains, in spite of fluctuations in virus accumulation. This indicates that the cross-protection effect of an attenuated virus is probably not affected by the presence of unrelated attenuated viruses in the plant. This also suggests that the protecting strain exhibits its ability when it has reached a minimum concentration or before it reaches its highest concentration. A certain time interval between protecting inoculations and challenge inoculations is necessary to establish cross-protection, and the degree of crossprotection is correlated with the concentrations of the protecting strain in the plants $(4,19,21)$. Our results support the former conclusion. However, the degree of crossprotection is unlikely to be associated with an increase or decrease in virus concentrations (shown in Figs. 1 and 2).

The cross-protection effectivenesses of CMV-mild and ZYMV-mild were not as good as that of WMV-mild, which was complete under greenhouse conditions. This was also demonstrated by the field experiments in our institute. However, in the grower's field experiments, superinfection of virulent CMV and ZYMV occurred at a low rate. The efficacy of WMVmild was different in 1994 and 1995. This may have been due to differences in properties between the virulent strains prepared in our laboratory and the local dominant strains, and/or to differences of disease pressure and spatiotemporal disease progression between the two locations.

Multiple inoculation largely protected grafted cucumber plants from wilt syndrome in the field experiments. This lethal syndrome was also prevented by single inoculation with a mild strain of ZYMV, $2 \mathrm{~S} 142 \mathrm{a} 6$, in the greenhouse experiments (7). The mechanism of wilt development due to viral infection on grafted plants has not been sufficiently elucidated. Iwasaki et al. (6) suggested that ZYMV multiplication initially induced occluded vessels attributable to tylosis in the grafted union and cucumber hypocotyl, resulting in impairment of water transport, and then CMV multiplication, enhanced by co-infection with ZYMV, led wilted plants to more severe wilt and death. None of the triply protective-inoculated plants developed wilt symptoms. They also exhibited almost no

Table 3. Cross-protection effectiveness of multiple inoculation in a grower's cucumber field

\begin{tabular}{|c|c|c|c|c|c|c|}
\hline \multirow[b]{2}{*}{ Plot } & \multirow{2}{*}{$\begin{array}{l}\text { Disease severity } \\
\text { in August }\end{array}$} & \multicolumn{3}{|c|}{ Infected plants $(\%)^{\mathrm{y}}$} & \multirow{2}{*}{$\begin{array}{l}\text { Plants showing } \\
\text { wilt (\%) }\end{array}$} & \multirow{2}{*}{$\begin{array}{c}\text { Marketable } \\
\text { fruits (kg/plant) }\end{array}$} \\
\hline & & $\overline{\mathrm{CMV}}$ & ZYMV & WMV-2 & & \\
\hline \multicolumn{7}{|l|}{$\overline{1994}$} \\
\hline Inoculated & $2.97 *^{\mathrm{z}}$ & $26.0^{*}$ & $8.0^{*}$ & $52.0^{*}$ & $0^{*}$ & $22.0^{*}$ \\
\hline Control & 4.03 & 84.0 & 66.0 & 98.0 & 51.7 & 13.7 \\
\hline \multicolumn{7}{|l|}{1995} \\
\hline Inoculated & $2.79 *$ & $14.0^{*}$ & 0 * & $12.0^{*}$ & $1.4^{*}$ & $22.7 *$ \\
\hline Control & 3.33 & 100 & 70.0 & 100 & 21.4 & 19.3 \\
\hline
\end{tabular}

y Percent infections by virulent strains of CMV, ZYMV, and WMV-2.

z Asterisks represent significant differences between two plots. Disease severity, disease incidence, and marketable fruits were statistically analyzed by the Kolmogorov-Smirnov two-sample test, Fisher's exact test or chi-square test of independence, and chi-square test of goodness of fit at $P=$ 0.05 , respectively. wilt symptoms after superinfection by virulent strains of ZYMV, CMV, and/or WMV-2. However, inoculation with the attenuated ZYMV alone or with three attenuated viruses may initially cause slight dysfunctions of vessels that don't cause wilt symptoms, so that new vessels probably continue to form. This initial shock reaction may induce or increase the tolerance of grafted plants to wilt.

The field experiments showed that the spread of the three attenuated viruses was limited. This would allow growers to better assess the risk of using multiple inoculation. Further work needs to be done to determine how to minimize the detrimental effects of this control measure. Such studies should include attempts to improve attenuated isolates, and investigations of cultivars and cultural practices for moderating yield loss due to protective inoculation.

\section{ACKNOWLEDGMENTS}

This project was supported by a grant from the Ministry of Agriculture, Forestry and Fisheries. We thank M. Kameya-Iwaki, M. Iwasaki, N. Hokama, and T. Shoji for generously providing virus isolates and antisera. We also thank I. Fujisawa and Y. Honda for helpful advice.

\section{LITERATURE CITED}

1. Clark, M. F. and Adams, A. N. 1977. Characteristics of the microplate method of enzymelinked immunosorbent assay for the detection of plant viruses. J. Gen. Virol. 34:475-483.

2. Hanada, K. 1995. Control of plant virus disease by attenuated virus and transgenic plant in Japan. Pg. 293-299 in: Proc. Int. Workshop on the Pest Management Strategies in Asian Monsoon Agroecosystems.

3. Hokama, N., Kawano, S., and Tokashiki, I. 1993. Effectiveness of cross protection by a mild strain of zucchini yellow mosaic virus for mosaic disease of pumpkin. (Abstr.) Ann. Phytopathol. Soc. Jpn. 59:323.

4. Huogen, X., Hweichung, F., and Kunghsun, L. 1995. Studies on the cross-protection among strains of papaya ringspot virus and its application in the disease control. Pg. 281291 in: Proc. Int. Workshop on the Pest Management Strategies in Asian Monsoon Agroecosystems.

5. Iwasaki, M. 1991. Wilt of cucumber plant grafted on squash rootstocks caused by the virus infections. Shokubutsu Boeki 45:419-422.

6. Iwasaki, M., and Inaba, T. 1988. Viral wilt of cucumber plants grafted on squash rootstocks. Ann. Phytopathol. Soc. Jpn. 54:584-592.

7. Iwasaki, M., Yamamoto, T., and Inaba, T. 1996. Wilt of cucumber plants grafted on squash rootstocks caused by viruses. Bull. Shikoku Natl. Agric. Exp. Stn. 60:1-60.

8. Kameya-Iwaki, M. 1994. Control of virus disease by attenuated viruses. Agric. Hortic. 69:137-142.

9. Kameya-Iwaki, M., Tochihara, H., Hanada, K., and Torigoe, H. 1992. Attenuated isolate of watermelon mosaic virus (WMV-2) and its cross protection against virulent isolate. Ann. Phytopathol. Soc. Jpn. 58:491-484.

10. Kono, T., Hanada, K., Shoji, T., KameyaIwaki, M., Zenbayashi, R., and Tochihara, H. 1989. Search of attenuated strains of cucumber mosaic virus for cucumber plant. Proc. Kanto Plant Prot. Soc. 36:52-53.

11. Kono, T., and Zenbayashi, R. 1988. The wilt symptoms caused by virus infection on grafted cucumber plants in Saitama Prefecture. Proc. Kanto Plant Prot. Soc. 35:58-59. 
12. Kosaka, Y., and Fukunishi, T. 1991. The occurrence of viral wilt disease on cucumber in Kyoto Prefecture. (Abstr.) Proc. Kansai Plant Prot. Soc. 33:132.

13. Kosaka, Y., and Fukunishi, T. 1993. Attenuated isolates of soybean mosaic virus derived at a low temperature. Plant Dis. 77:882-886.

14. Kosaka, Y., Fukunishi, T., Hokama, N., Fujisawa, I., and Kameya-Iwaki, M. 1993. Protective effect of a mixed preinoculation with attenuated isolates of cucumber mosaic virus, watermelon mosaic virus 2 and zucchini yellow mosaic virus on cucumber. (Abstr.) Ann. Phytopathol. Soc. Jpn. 59:324.

15. Kosaka, Y., Fukunishi, T., Hokama, N., Fujisawa, I., and Kameya-Iwaki, M. 1994. Effectiveness of a mixed preinoculation with attenuated isolates of cucumber mosaic virus, watermelon mosaic virus 2 and zucchini yellow mosaic virus on cucumber in fields. (Abstr.) Ann. Phytopathol. Soc. Jpn. 60:401.

16. Kosaka, Y., Fukunishi, T., Hokama, N., Fujisawa, I., and Kameya-Iwaki, M. 1995. Evaluation of cross-protection strategy with three attenuated isolates of cucumber mosaic virus, watermelon mosaic virus 2 and zucchini yellow mosaic virus for the control of cucumber virus disease. (Abstr.) Ann. Phytopathol. Soc. Jpn. 61:271.

17. Kosaka, Y., Yoshida, T., Shirota, K., Fukunishi, T., Hokama, N., and Kameya-Iwaki, M. 1996. Benefits assessment of cross-protection strategy with three attenuated isolates of cucumber mosaic virus, watermelon mosaic virus 2 and zucchini yellow mosaic virus for the control of cucumber virus disease. (Abstr.)
Ann. Phytopathol. Soc. Jpn. 62:322-323.

18. Poolpol, P., and Inoue, T. 1986. Enhancement of cucumber mosaic virus multiplication by zucchini yellow mosaic virus in doubly infected cucumber plants. Ann. Phytopathol. Soc. Jpn. 52:22-30.

19. Wen, F., Lister, R. M., and Fattouh, F. A 1991. Cross-protections among strains of barley yellow dwarf virus. J. Gen. Virol. 72:791-799.

20. Yamamoto, T., Ishii, M., Katsube, T., and Ohata, K. 1984. Epidemiological studies of watermelon mosaic virus. Bull. Shikoku Natl. Agric. Exp. Stn. 44:26-140.

21. Yeh, S.-D., and Gonsalves, D. 1984. Evaluation of induced mutants of papaya ringspot virus for control by cross protection. Phytopathology 74:1086-1091. 